\title{
Source characteristics of shallow intraslab earthquakes derived from strong-motion simulations
}

\author{
Kimiyuki Asano, Tomotaka Iwata, and Kojiro Irikura \\ Disaster Prevention Research Institute, Kyoto University, Kyoto 611-0011, Japan \\ (Received February 4, 2003; Revised March 25, 2003; Accepted March 31, 2003)
}

\begin{abstract}
Source modeling of recent shallow intraslab earthquakes is studied using strong-motion data. The total area of strong-motion generation areas obtained is smaller than the prediction from the empirical relationship for inland crustal earthquakes by Somerville and co-workers. Moreover, the ratio between the combined area of strong-motion generation areas obtained in this study and the area predicted by the empirical relationship, tends to decrease with focal depth. The stress drops on strong motion generation areas (or asperities) of shallow intraslab earthquakes increase with focal depth.
\end{abstract}

Key words: Shallow intraslab earthquake, strong-motion generation, empirical Green's function method, stress drop.

\section{Introduction}

Japan is located along major subduction zones where historically large shallow intraslab earthquakes have occurred below populated areas causing severe damage through strong ground motions (e.g., the 1993 Kushiro-Oki earthquake). Previous studies on source characteristics and stress drops for intraslab earthquakes have been conducted by e.g., Mikumo (1971), Wyss and Molnar (1972), Chung and Kanamori (1980), Fukao and Kikuchi (1987), Campus and Das (2000), and Houston (2001). They mainly analyzed intermediate depth earthquakes $(70-300 \mathrm{~km})$ or deep earthquakes $(300-670 \mathrm{~km})$. In most of these studies, the durations of source-time functions of long-period body waves or the corner frequencies of source spectra were used to estimate source dimensions and stress drops. Shallow intraslab earthquakes, which occur within the subducting plates at a depth of 30-70 km, have rarely been examined with the exception of several recent large earthquakes (Kakehi and Yamauchi, 2001).

Kanamori and Anderson (1975) gathered sets of seismic moments and source dimensions from numerous papers to study source characteristics based on a theoretical background. They concluded that the average stress drops in rupture areas of intraplate events were $10 \mathrm{MPa}$, which were higher than interplate events $(3 \mathrm{MPa})$ with comparable seismic moments, and that the fault surface areas of intraplate events were smaller than those of interplate events.

This study estimated source models for several moderatesize and large shallow intraslab earthquakes occurring around Japan using strong-motion network data. Then, the relationship between the combined area of asperities and seismic moment for these intraslab earthquakes was compared with the empirical relationship for inland crustal earth-

Copy right(C) The Society of Geomagnetism and Earth, Planetary and Space Sciences (SGEPSS); The Seismological Society of Japan; The Volcanological Society of Japan; The Geodetic Society of Japan; The Japanese Society for Planetary Sciences. quakes proposed by Somerville et al. (1999). The focal depth dependence of the asperity size was also examined.

\section{Analysis Method and Data}

Source models of six recent shallow intraslab earthquakes that occurred around Japan were analyzed using near-source strong-motion records (Table 1 and Fig. 1). The hypocenters of these events were located at a depth of 30-70 km within the Philippine Sea slab or the Pacific slab.

Broadband strong motion simulation was conducted using the empirical Green's function method for estimating source models (Irikura, 1986; Miyake et al., 1999). Waveform records of a small event with a hypocenter that was close to that of a target event and a focal mechanism that was similar to that of the target event, were used as the empirical Green's functions.

To explain the observed waveforms in the broadband frequency range, horizontal components of acceleration, velocity, and displacement waveforms at four stations around the source region were simulated. A characterized source model with several rectangular strong motion generation areas (SMGA) within the rupture area was created and strong motions were assumed to radiate only from these SMGAs (e.g., Kamae and Irikura, 1998a). The size of SMGAs, rise time, and rupture velocity were estimated using a forward modeling. An appropriate fault plane was also selected with reference to the results of moment tensor inversions determined by F-net or Harvard University. Radial rupture propagation from the hypocenter located by the Japan Meteorological Agency (JMA) was assumed. Each model parameter was determined in a certain range which was set empirically (e.g., rupture propagation velocity was searched from $0.6 \beta$ to 0.9 $\beta$, where $\beta$ was the shear wave velocity at the source region). The best fitting model was determined to be the model that had minimum residuals of displacement waveforms and those of envelopes of acceleration waveforms (Miyake et al. 1999). 
Table 1. Hypocentral information for target events and empirical Green's function events determined by JMA.

\begin{tabular}{ccccccccccc}
\hline \multicolumn{3}{l}{ Target event } & \multicolumn{10}{c}{ Empirical Green's function event } \\
\hline $\begin{array}{c}\text { Event } \\
\text { No. }\end{array}$ & Origin time & $\begin{array}{c}\text { Lat. } \\
(\text { deg. })\end{array}$ & $\begin{array}{c}\text { Long. } \\
(\text { deg. })\end{array}$ & $\begin{array}{c}\text { Depth } \\
(\mathrm{km})\end{array}$ & $M_{J}$ & Origin time & $\begin{array}{c}\text { Lat. } \\
(\text { deg. })\end{array}$ & $\begin{array}{c}\text { Long. } \\
(\text { deg. })\end{array}$ & $\begin{array}{c}\text { Depth } \\
(\mathrm{km})\end{array}$ & $M_{J}$ \\
\hline 1 & $1997 / 03 / 1614: 51$ & 34.925 & 137.528 & 39.1 & 5.8 & $1997 / 03 / 1614: 53$ & 34.901 & 137.515 & 36.2 & 4.3 \\
2 & $1999 / 08 / 2105: 33$ & 34.028 & 135.473 & 65.8 & 5.4 & $2000 / 06 / 0215: 05$ & 34.002 & 135.407 & 59.9 & 4.1 \\
3 & $2000 / 01 / 2823: 21$ & 43.056 & 146.749 & 58.5 & 7.0 & $2000 / 09 / 0320: 01$ & 42.984 & 146.846 & 49.4 & 5.2 \\
4 & $2001 / 03 / 2415: 27$ & 34.129 & 132.696 & 46.5 & 6.7 & $2001 / 03 / 2605: 40$ & 34.114 & 132.712 & 45.9 & 5.0 \\
5 & $2001 / 04 / 0323: 57$ & 35.021 & 138.097 & 30.3 & 5.1 & $2001 / 04 / 0400: 04$ & 35.011 & 138.089 & 31.3 & 4.3 \\
6 & $2001 / 04 / 2523: 40$ & 32.796 & 132.342 & 39.3 & 5.6 & $1999 / 01 / 2505: 05$ & 32.694 & 132.286 & 39.2 & 4.0 \\
\hline
\end{tabular}

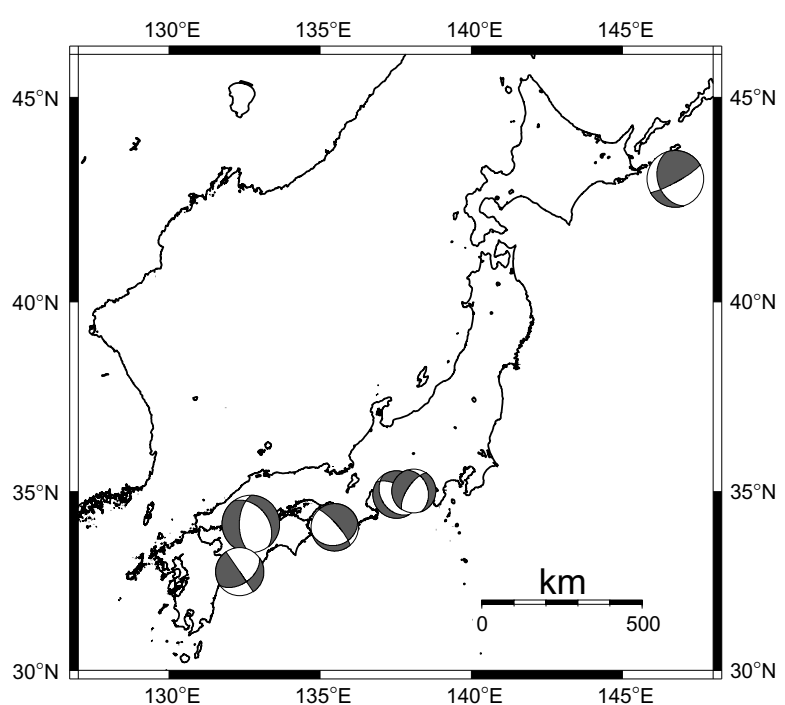

Fig. 1. Locations of epicenters and focal mechanisms (lower hemisphere projection) used in this study. The center of the focal sphere indicates the epicenter of the corresponding event. These focal mechanisms were determined from the moment tensor inversion by F-net (http://www.fnet.bosai.go.jp/) and Harvard University (http: //www. seismology. harvard. edu/projects/CMT/)

The upper limit of the frequency range used in this simulation was fixed at $10 \mathrm{~Hz}$. The lower limit was determined by the appropriate signal-to-noise ratio of the small event data, which ranged from 0.2 to $0.7 \mathrm{~Hz}$.

\section{Results}

The source parameters obtained in this study are shown in Table 2. An example of the comparison of observed and synthetic waveforms is shown in Fig. 2. Results are sufficiently reliable in the broadband range to achieve the aims of this study. Each event has one SMGA except event No. 4 (the 2001 Geiyo earthquake). Assuming two SMGAs for the 2001 Geiyo earthquake, the observed waveform and duration at each station can be explained fairly well.

The relationship between the combined area of SMGAs obtained in this study and seismic moment is shown in Fig. 3. Results from other studies using the same method of analysis are also indicated.

The solid line in Fig. 3 is the empirical relationship between combined area of asperities and seismic moment for inland crustal earthquakes from the waveform inversion results compiled by Somerville et al. (1999). They character-
Table 2. Source parameters obtained in this study and seismic moment determined by F-net.

\begin{tabular}{ccccccc}
\hline $\begin{array}{c}\text { Event } \\
\text { No. }\end{array}$ & $\begin{array}{c}L \\
(\mathrm{~km})\end{array}$ & $\begin{array}{c}W \\
(\mathrm{~km})\end{array}$ & $\begin{array}{c}S_{a} \\
\left(\mathrm{~km}^{2}\right)\end{array}$ & $\begin{array}{c}V_{r} \\
(\mathrm{~km} / \mathrm{s})\end{array}$ & $\begin{array}{c}t_{r} \\
(\mathrm{sec})\end{array}$ & $\begin{array}{c}M_{0} \\
(\mathrm{Nm})\end{array}$ \\
\hline 1 & 1.5 & 1.8 & 2.7 & 3.1 & 0.09 & $2.97 \times 10^{17}$ \\
2 & 1.2 & 1.2 & 1.4 & 4.2 & 0.04 & $2.79 \times 10^{17}$ \\
3 & 4.4 & 5.6 & 24.6 & 3.7 & 0.12 & $1.21 \times 10^{19}$ \\
$4(\# 1)$ & 7.2 & 4.6 & 33.1 & 2.7 & 0.24 & \\
$4(\# 2)$ & 5.4 & 4.6 & 24.8 & 2.7 & 0.18 & \\
4 (total) & & & 58.0 & & & $1.51 \times 10^{19}$ \\
5 & 1.8 & 2.2 & 4.0 & 3.1 & 0.04 & $8.17 \times 10^{16}$ \\
6 & 2.2 & 3.4 & 7.5 & 3.4 & 0.12 & $4.00 \times 10^{17}$ \\
\hline
\end{tabular}

$L, W$, and $S_{a}$ are length, width, and area of SMGA for each event, respectively. $t_{r}$ and $V_{r}$ are rise time and rupture propagation velocity. The seismic moment of the target event $M_{0}$ was obtained from moment tensor inversions using broad band waveform data by F-net (Fukuyama et al., 1998).

ized an asperity as the area that has a 1.5 times larger slip relative to the average slip on the rupture area, and constructed this empirical relationship by quantifying such asperities in a deterministic manner from the heterogeneous spatial slip distributions derived from the kinematic waveform inversion. The SMGA estimated from forward modeling based on the broadband strong motion simulation coincides fairly well with the asperity derived from the waveform inversion (Kamae and Irikura, 1998a; Miyakoshi et al., 2000; Miyake et al., 2001). Henceforth, SMGA will be treated as asperity in this paper. The relationship between stress drop and asperity area is expressed by

$$
\Delta \sigma_{a}=C \frac{M_{0}}{S_{a}^{3 / 2}}
$$

where $\Delta \sigma_{a}$ is the stress drop on asperities, and $S_{a}$ is the combined area of asperities. When the ratio of seismic moment on asperities with respect to total seismic moment is assumed to be constant (Somerville et al., 1999), the combined area of asperities when the stress drop on asperities is five times higher than the empirical relationship for an inland crustal earthquake for a comparable seismic moment $S_{a}^{\prime \prime}$, is obtained by

$$
S_{a}^{\prime \prime}=\frac{1}{5^{2 / 3}} S_{a}^{\prime}
$$

$S_{a}^{\prime}$ is the combined area of asperities predicted by Somerville et al. (1999) for the given seismic moment. The relationship between $M_{0}$ and $S_{a}^{\prime \prime}$ is indicated by the dotted line in Fig. 3. 

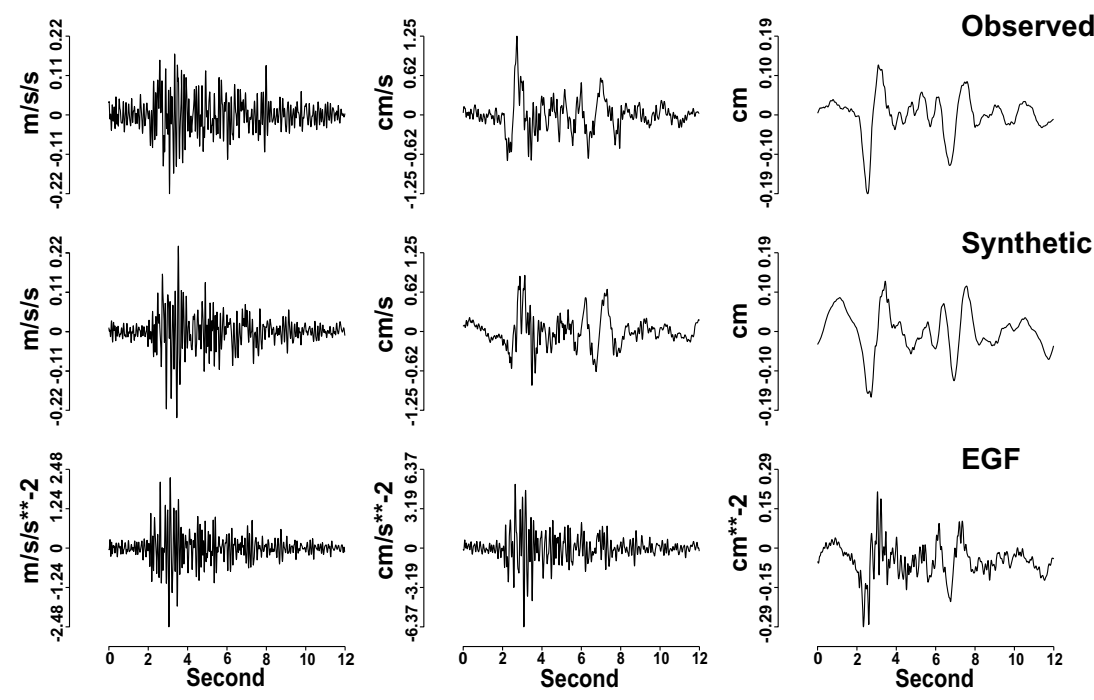

Fig. 2. Observed and synthetic waveforms of NS components at station KOC016 (K-NET) for event No. 6. The upper row is observed, the middle row is the synthetic waveform for the target event, and the lower row is the empirical Green's function (EGF). Left, center, and right columns are acceleration, velocity, and displacement waveforms, respectively.

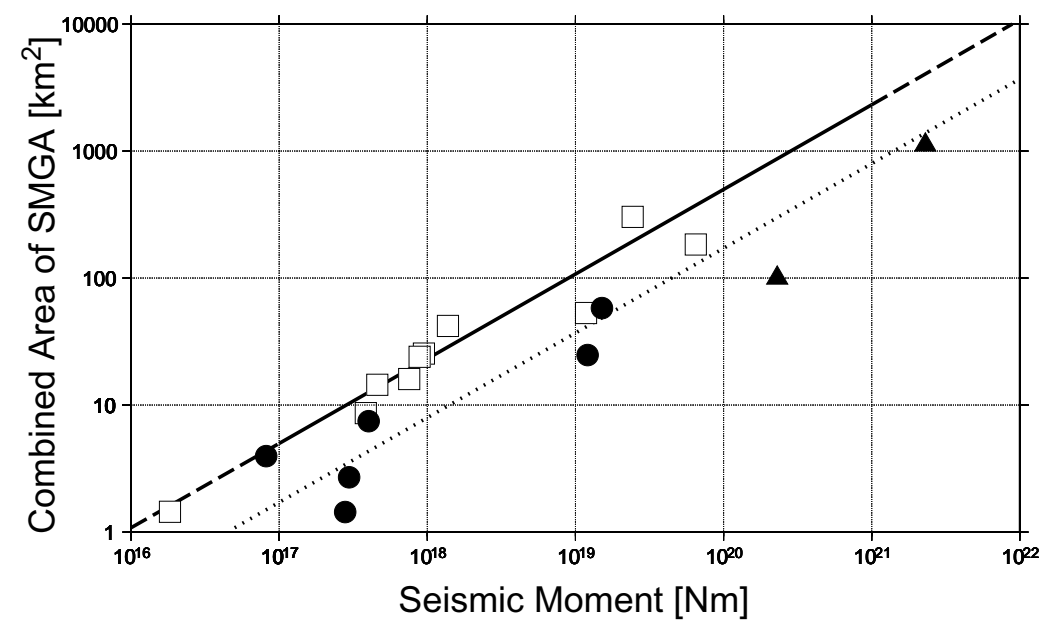

Fig. 3. Relationship between the combined area of SMGAs and seismic moment. Solid circles, solid triangles, and open squares indicate intraslab earthquakes obtained in this study, large intraslab earthquakes in Hokkaido, Japan (Morikawa and Sasatani, 2001), and inland crustal earthquakes (Kamae and Irikura, 1998a, 1998b; Miyake et al., 2001; Birgoren et al., 2001), respectively. The solid line indicates the empirical relationship between the combined area of asperities and seismic moment for inland crustal earthquakes by Somerville et al. (1999). The broken portion is the extension of the relationship for smaller and larger events. The dotted line is the relationship when the stress drop on the asperities is five times higher than that of the empirical relationship.

\section{Discussion}

The combined area of asperities for these shallow intraslab earthquakes was estimated to be $14-90 \%$ of values predicted from the empirical relationship for crustal events (Fig. 3). The combined area of asperities of shallow intraslab earthquake is smaller than that of inland crustal earthquakes with comparable seismic moments, although the difference between the obtained values and the empirical relationship varies for each event.

In Fig. 4, the ratios $S_{a} / S_{a}^{\prime}$ are plotted against focal depths on a logarithmic scale, where $S_{a}$ is the combined area of asperities obtained in this study. The $S_{a} / S_{a}^{\prime}$ value decreases with focal depth. These results mean that as the focal depth increases, the stress drop of a shallow intraslab earthquake is higher.

The physical explanation is not yet apparent, but the phys- ical properties of the focal region are thought to change with depth. Bilek and Lay (1999) studied the relation between source durations and depths using point-source waveform inversions of teleseismic broadband records from interplate thrust events occurring in the Japan Trench and concluded that an increase in stress drops with increasing depth was caused by rigidity variations along the interface. If the rigidity of the slab increases with depth, the stress drop will increase. Our results for shallow intraslab events are similar to their results for interplate events.

Mikumo (1971) suggested that the stress drops for intermediate and deep focus earthquakes tend to increase with depth and that a linear relationship may apply when values are plotted with respect to hydrostatic pressures at appropriate depths. Aside from the problem of whether the stress drops of intermediate and deep earthquakes change 




Fig. 4. Relationship between $S_{a} / S_{a}^{\prime}$ and focal depth for intraslab earthquakes. Solid circles and triangles indicate the results from this study and Morikawa and Sasatani (2001), respectively. Solid lines indicate the spatial extent of asperities in the direction of depth.

with depth or not, other studies have commonly mentioned that intermediate and deep earthquakes have relatively higher stress drops than shallower earthquakes. At a minimum, the transitional zone of stress drops from low stress drops to high stress drops at the depths that were investigated in this study is apparent.

\section{Conclusions}

Source models for six shallow intraslab earthquakes that occurred around Japan were constructed via forward modeling using the empirical Green's function method. These results indicate that the combined area of asperities is smaller than the prediction by the empirical relationship for inland crustal earthquakes. These results are consistent with recent results for several large intraslab earthquakes. Moreover, stress drops of the asperities seem to depend on the focal depth, which is an important characteristic of shallow intraslab earthquakes. Although the number of analyzed events was small, focal depth dependence was noted. Future research may separate the focal-depth dependence from other factors with more event analyses in the same manner.

Acknowledgments. We would like to sincerely thank the K-NET, KiK-net, and F-net operated by the National Research Institute for Earth Science and Disaster Prevention (NIED) for providing the strong motion data and the moment tensor solutions, Harvard University for providing moment tensor solutions, and the Japan Meteorological Agency (JMA) for providing the hypocentral information. Further, we would also like to thank Hiroe Miyake for allowing us use of a program for the empirical Green's function method and helpful discussion and James Mori for improvement of the manuscript. We are grateful to Masayuki Kikuchi and an anonymous referee for constructive comments which led us to improve the manuscript. We used Generic Mapping Tools Ver. 3.0 (Wessel and Smith, 1995) to draw several figures in this paper. This study is partially supported by MEXT's Special Coordination Fund
(2000-2004) under the title 'Study on the master model for strong ground motion prediction toward earthquake disaster mitigation' and Grants-in-Aid for Scientific Research in priority area (B) No. 11209201 (PI. T. Iwata).

\section{References}

Bilek, S. L. and T. Lay, Comparison of depth dependent fault zone properties in the Japan Trench and Middle America Trench, Pure Appl. Geophys. 154, 433-456, 1999.

Birgoren, G., H. Miyake, and K. Irikura, Source model of 1999 November 12 Duzce, Turkey earthquake using empirical Green's function method, Eos Trans. Am. Geophys. Union, 82(47), Fall Meet. Suppl., Abstract S52E-0689, 2001.

Campus, P. and S. Das, Comparison of the rupture and radiation characteristics of intermediate and deep earthquakes, J. Geophys. Res., 105, $6177-$ 6189, 2000.

Chung, W.-Y. and H. Kanamori, Variation of seismic source parameters and stress drops within a descending slab and its implications in plate mechanics, Phys. Earth Planet. Inter., 23, 134-159, 1980.

Fukao, Y. and M. Kikuchi, Source retrieval for mantle earthquakes by iterative deconvolution of long-period P-waves, Tectonophys., 144, 249-269, 1987.

Fukuyama, E., M. Ishida, D. S. Dreger, and H. Kawai, Automated seismic moment tensor determination by using on-line broadband waveforms, Zisin 2 (J. Seism. Soc. Jpn.), 51, 149-156, 1998 (in Japanese with English abstract).

Houston, H., Influence of depth, focal mechanism, and tectonic setting on the shape and duration of earthquake source time functions, J. Geophys. Res., 106, 11137-11150, 2001

Irikura, K., Prediction of strong acceleration motions using empirical Green's function, Proc. 7th Japan Earthq. Eng. Symp., 151-156, 1986.

Kakehi, Y. and M. Yamauchi, Source modeling of a slab earthquake in the subducting Philippine Sea plate using strong ground motion records of high-density observation networks, Eos Trans. Am. Geophys. Union, 82(47), Fall Meet. Suppl., Abstract S42C-0679, 2001.

Kamae, K. and K. Irikura, Source model of the 1995 Hyogo-ken Nanbu earthquake and simulation of near-source ground motion, Bull. Seism. Soc. Am. 88, 400-412, 1998a.

Kamae, K. and K. Irikura, A source model of the 1994 Northridge earthquake $\left(\mathrm{M}_{\mathrm{W}}=6.7\right)$, Proc. 10th Japan Earthq. Eng. Symp., 643-648, 1998 b (in Japanese).

Kanamori, H. and D. L. Anderson, Theoretical basis of some empirical relations in seismology, Bull. Seism. Soc. Am., 65, 1073-1095, 1975.

Mikumo, T., Source process of deep and intermediate earthquakes as inferred from long-period $\mathrm{P}$ and $\mathrm{S}$ waveforms: 2 Deep-focus and intermediate-depth earthquakes around Japan, J. Phys. Earth, 19, 303320, 1971 .

Miyake, H., T. Iwata, and K. Irikura, Strong ground motion simulation and source modeling of the Kagoshima-ken Hokuseibu earthquakes of March 26( $\left.M_{J M A} 6.5\right)$ and May $13\left(M_{J M A} 6.3\right), 1997$, using empirical Green's function method, Zisin 2 (J. Seism. Soc. Jpn.), 51, 431-442, 1999 (in Japanese with English abstract).

Miyake, H., T. Iwata, and K. Irikura, Estimation of rupture propagation direction and strong motion generation area from azimuth and distance dependence of source amplitude spectra, Geophys. Res. Lett., 28, 2727 2730, 2001.

Miyakoshi, K., T. Kagawa, H. Sekiguchi, T. Iwata, and K. Irikura, Source characterization of inland earthquakes in Japan using source inversion results, Proc. 12th World Conf. Earthq. Eng., 1850, 2000.

Morikawa, N. and T. Sasatani, Source models of great intra-slab earthquakes using the empirical Green's function method, Abstr. 2001 Japan Earth and Planet. Sci. Joint Meet. [CD-ROM], Sp-P011, 2001.

Somerville, P., K. Irikura, R. Graves, S. Sawada, D. Wald, N. Abrahamson, Y. Iwasaki, T. Kagawa, N. Smith, and A. Kowada, Characterizing crustal earthquake slip models for the prediction of strong ground motion, Seism. Res. Lett., 70, 59-80, 1999.

Wessel, P. and W. H. F. Smith, New version of the Generic Mapping Tools released, Eos Trans. Am. Geophys. Union, 76, 329, 1995.

Wyss, M. and P. Molnar, Source parameters of intermediate and deep focus earthquakes in the Tonga arc, Phys. Earth Planet. Inter., 6, 279-292, 1972.

K. Asano (e-mail: k-asano@egmdpri01.dpri.kyoto-u.ac.jp), T. Iwata, and $\mathrm{K}$. Irikura 